\title{
Comparing steam-flaked and pelleted barley grain in a feed-first guided-flow automated milking system for Holstein cows
}

\author{
J. A. Johnson, ${ }^{1} \odot$ K. S. Paddick, ${ }^{1,2}$ M. Gardner, ${ }^{1} \oplus$ and G. B. Penner ${ }^{1 *} \oplus$ \\ ${ }^{1}$ Department of Animal and Poultry Science, University of Saskatchewan, Saskatoon, SK, Canada S7N 5A8 \\ ${ }^{2}$ More Than Just Feed Inc., Strathmore, AB, Canada T1P 1Y4
}

\section{ABSTRACT}

Provision of a palatable feed in automated milking systems (AMS) is considered an essential motivating factor to encourage voluntary visits to the milking stall. Although the quantity and composition of AMS concentrates have been previously investigated, the form of the concentrate has not been extensively evaluated. The objective of this study was to evaluate the effects of feeding pelleted (PB; $132.9 \pm 56 \mathrm{DIM}, 47.4 \pm 9.51 \mathrm{~kg} / \mathrm{d}$ milk yield) versus steam-flaked barley (SFB; $133.0 \pm 63$ DIM, $40.5 \pm 8.23 \mathrm{~kg} / \mathrm{d}$ milk yield) in an AMS on dry matter intake, AMS visits, milk and milk component yield, and partial mixed ration (PMR) feeding behavior. Twenty-nine Holstein cows of varying parities were enrolled in this study. Cows were housed in freestall housing with a feed-first guided-flow barn design; 7 cows were housed in a separate freestall pen to enable individual PMR intake and feeding behavior monitoring. This study was conducted as a 2-way crossover, with two 21-d periods in which each cow received the same basal PMR but was offered $2 \mathrm{~kg} / \mathrm{d}$ (dry matter basis) of $\mathrm{PB}$ or SFB in the AMS. Cows receiving the SFB had fewer voluntary AMS visits (2.71 vs. $2.90 \pm$ 0.051, no./d), tended to have a longer interval between milkings (541.7 vs. $505.8 \pm 21.02 \mathrm{~min}$ ), spent more time in the holding pen before entering the AMS (139.9 vs. $81.2 \pm 11.68 \mathrm{~min} / \mathrm{d}$ ), and had lower total box time (19.7 vs. $21.4 \pm 0.35 \mathrm{~min} / \mathrm{d}$ ) than cows fed PB. Despite changes in AMS attendance, there were no differences for average milk $(44.0 \mathrm{~kg} / \mathrm{d})$, fat $(1.62 \mathrm{~kg} / \mathrm{d})$, and protein $(1.47 \mathrm{~kg} / \mathrm{d})$ yields or AMS concentrate intake $(2.02$ $\mathrm{kg} / \mathrm{d}$ ). These behavioral changes indicate that offering $\mathrm{SFB}$ as an alternative to $\mathrm{PB}$ may reduce motivation for cows to voluntarily enter the AMS.

Key words: feeding behavior, milking behavior, robotic milking, pellet

\footnotetext{
Received March 2, 2021.

Accepted August 23, 2021.

*Corresponding author: greg.penner@usask.ca
}

\section{INTRODUCTION}

Since their first installation in 1992 (de Koning, 2011), automated milking systems (AMS) have been installed on more than 35,000 dairy farms worldwide (Salfer et al., 2019). With AMS, frequent and consistent visits are thought to be encouraged by the provision of a palatable feed in the AMS (Jacobs and Siegford, 2012; Bach and Cabrera, 2017). There is a common perception in the industry that providing a greater quantity of feed in the AMS may equate to an increased desire to enter the AMS. However, with $7 \mathrm{~min} /$ milking (Castro et al., 2012), pellet consumption rates between 250 and 400 $\mathrm{g} / \mathrm{min}$ (Kertz et al., 1981), and an average of 3 visits to the AMS per day (Bach et al., 2009; Deming et al., 2013; Paddick et al., 2019), AMS provisions $>8 \mathrm{~kg} / \mathrm{d}$ are unlikely to be completely delivered or consumed. As a result, studies have reported that the discrepancy between the amount of feed programmed for delivery in the AMS, the amount delivered, and the amount consumed increases with increasing concentrate allocation in the AMS (Henriksen et al., 2019; Paddick et al., 2019). In addition, feeding management in the AMS may affect partial mixed ration (PMR) formulation and PMR feeding behavior (Menajovsky et al., 2018; Paddick et al., 2019), suggesting that a comprehensive evaluation of AMS feeding management must include PMR feeding behavior.

Although several studies have focused on determining an ideal quantity (Migliorati et al., 2005; Henriksen et al., 2018) or composition (Halachmi et al., 2006; Madsen et al., 2010) of the concentrate offered in the AMS to support voluntary attendance, few have evaluated the form of concentrate provision. Concentrate in the AMS is generally provided in pellet form, based on studies by Spörndly and Åsberg (2006) demonstrating that cows had a preference for concentrate provided as a pellet versus mash or meal form. In contrast, Migliorati et al. (2005) demonstrated that at low feeding levels (1.4 $\mathrm{kg} / \mathrm{d}$ ), visits to the AMS were not influenced when the pellet was formulated with or without a flavor additive, suggesting the possibility of more flexibility for feed 
options when offering low quantities of concentrate in the AMS.

Use of pelleted feeds restricts opportunity for use of feeds produced on farm and may increase cost. To reduce associated feed costs, a survey-based study indicated that some producers may already be experimenting with alternatives to pellets with the use of simpler feed ingredients such as meals or processed grain mixtures produced on farm (de Jong et al., 2003). When offered at lower feeding levels, producers may have more flexibility to use other feed forms without compromising visits to the AMS or production parameters. Supporting this concept, Henriksen et al. (2018) observed an increase in AMS visits and increased milk yield when cows were offered the mixture of pellet and steam-rolled barley relative to the pellet-only concentrate. Cost-saving opportunities may exist for producers interested in offering simpler feed in the AMS, but, to the authors' knowledge, currently no available studies have evaluated the provision of single-commodity concentrates in the AMS and possible effects on milk production parameters. Moreover, the authors are not aware of any other studies that have simultaneously evaluated the form of AMS concentrate as well as PMR feeding behavior.

The null hypothesis was that form of concentrate in the AMS would not influence DMI, AMS visits, or milk and milk component yield, and that no change in milking or PMR feeding behavior would occur. Thus, the objectives of the current study were to determine whether the form of AMS concentrate provision [steamflaked barley (SFB) vs. pelleted barley (PB)] resulted in changes in DMI, AMS intake, voluntary AMS visits, milking behavior, PMR feeding behavior, and milk and milk component yield.

\section{MATERIALS AND METHODS}

\section{Cows and Facility Design}

Care and use of cows in this experiment was approved by the University of Saskatchewan Research Ethics Board (Saskatoon, SK; protocol no. 20100021) in accordance with the guidelines from the Canadian Council on Animal Care (Ottawa, ON, Canada). The study was conducted from May to July 2018, using a total of 22 cows averaging $142 \pm 62$ DIM (14 primiparous cows, 5 cows in second lactation, and 3 cows in their third or greater lactation) that were group housed (large housing group, LG) with up to an additional 18 cows in a freestall barn (50 stalls). An additional small housing group (SM) of 7 cows (second lactation; average $108 \pm 38$ DIM) was housed in a freestall pen with 12 stalls. For cows in the SM housing group, a single parity was purposely chosen to avoid parity effects within that housing group. Cows were included as part of the study data set based on prior training to the AMS and provided that their milking permissions (described subsequently) did not change during the study. Both groups of cows were housed in a feedfirst guided traffic flow design at the Rayner Dairy Research and Teaching Facility (Saskatoon, SK, Canada) and accessed the same AMS (Model, Classic; DeLaval, Tetra Laval Group) through a common holding area. Following milking, cows were directed to their housing area via sort gates. All stalls had mattresses with wood shavings as bedding. Cows in the LG group accessed the PMR through a common feed bunk with 49 headlock positions, whereas cows in the SM group were individually assigned to a single Insentec bunk (Hokofarm Group) to allow for individual measurement of PMR intake and feeding behavior. Cows were trained to use their respective Insentec bunk for at least $7 \mathrm{~d}$ before the start of the study.

For both housing groups, cows left the freestall area by passing through a one-way gate to enter the feeding area. Cows then passed through a sort gate, which directed cows either to the common AMS holding area to gain access to the AMS or back to their respective freestall area, based on milking permission criteria. Milking permission was granted based on DIM and predicted milk yield at the time of entering the sort gate, with cows $<51$ DIM having permission to enter the AMS every $5 \mathrm{~h}$ or if expected milk production was $>9$ $\mathrm{kg}$ of milk, cows from 51 to 265 DIM allowed to enter the AMS every $7 \mathrm{~h}$ or when expected yield was $>9 \mathrm{~kg}$, and cows $>265$ DIM allowed to enter the AMS every 9 $\mathrm{h}$ or if expected milk yield was $>11 \mathrm{~kg}$. These milking criteria were used to prioritize milking access for cows in early lactation and for those with greater milk yield. No cows changed milking permissions throughout the duration of the study. If cows did not voluntarily enter the AMS within $12 \mathrm{~h}$ of their last milking for early lactation ( $<51$ DIM) or mid-lactation (51-265 DIM), or $14 \mathrm{~h}$ for cows in late lactation ( $>265$ DIM), they were fetched into the holding area to be milked. Fetching occurred at 0430, 1230, and $2030 \mathrm{~h}$, and fetched cows were recorded. Fetching and general management activity were completed by farm staff blinded to treatments. To minimize time spent in the holding area, a maximum of 10 cows were permitted to be in the holding area at one time, unless $4 \mathrm{~h}$ had elapsed since gaining milking permission, upon which cows could enter the holding area regardless of the number of cows present. 


\section{Study Design}

The study was designed as a crossover design including an initial 7-d covariate period used to account for potential differences in initial milk yield. The crossover study periods were planned to be $21 \mathrm{~d}$ in duration, including $15 \mathrm{~d}$ for dietary adaptation and $6 \mathrm{~d}$ for data and sample collection. This timeline was achieved for period 1, but technical issues with the AMS delayed collections by $7 \mathrm{~d}$ during period 2 , resulting in an actual period duration of $28 \mathrm{~d}$, with $22 \mathrm{~d}$ of dietary adaptation and $6 \mathrm{~d}$ of data and sample collection. Cows were stratified by parity and DIM at the start of the study, and, within strata, were randomly assigned to 1 of 2 treatment sequences. This stratification and treatment assignment resulted in a pre-study mean of $133 \pm 63$ DIM (mean \pm SD) and a milk yield of $40.5 \pm 8.3 \mathrm{~kg} / \mathrm{d}$ for cows assigned to the SFB treatment and $132.9 \pm 56$ DIM with a milk yield of $47.2 \pm 9.5 \mathrm{~kg} / \mathrm{d}$ for cows assigned to the PB treatment in period 1. Power analysis was conducted to determine the sample size required to detect a difference of 0.3 visits per day in milking frequency (3.0 vs. 2.7 with $\mathrm{SD}=0.3$ ), with a nominal power of $80 \%$ and $\alpha=0.05$ (Menajovsky et al., 2018; Paddick et al., 2019). An additional consideration was to ensure that the capacity of the AMS was representative of those used in commercial practice in Canada (47.5 cows per AMS; Matson et al., 2021).

Dietary treatments (PMR and AMS concentrate; Table 1) were common for both housing groups, and the total diet was formulated to meet the nutrient requirements for a $680-\mathrm{kg}$ cow with an expected DMI of $26 \mathrm{~kg} / \mathrm{d}$, with a milk yield of $40 \mathrm{~kg}$, containing $4.0 \%$ fat and $3.2 \%$ total protein using the Cornell Net Carbohydrate and Protein System (6.55) platform of Nutritional Dynamic System (RUM\&N Sas). The diet included 2.0 $\mathrm{kg} / \mathrm{d}$ (DM basis) of either PB or SFB provided in the AMS. The AMS used 2 separate feed bins and augers, allowing delivery of up to 2 different concentrates to individual cows. Barley grain used for both treatments was obtained from the same single source (Canadian Feed Research Centre, North Battleford, SK, Canada). Although a single commodity feed is not a common feeding approach in AMS, use of barley as the sole ingredient allowed for the production of 2 forms of the AMS feed, while minimizing differences in composition and production of fine particles. Past research has also shown preference of cattle for barley-based pellets (Madsen et al., 2010).

To achieve the target AMS concentrate consumption of $2 \mathrm{~kg} / \mathrm{d}$ (DM basis), the amount of concentrate offered in the AMS was adjusted every fourth day, based on average AMS intake during the previous $3 \mathrm{~d}$. To meet the $2 \mathrm{~kg} / \mathrm{d}$ target, the amount programmed to be delivered was $2.08 \mathrm{~kg} / \mathrm{d}$ (range 1.97-2.29 kg/d, DM basis), greater than the target to correct for the probability of cows not achieving their full daily allocation. This approach has been used successfully in previous studies (Menajovsky et al., 2018; Paddick et al., 2019). The amount of concentrate delivered at each visit to the AMS was recorded by the AMS software (DelPro 4.5, DeLaval, Tetra Laval Group) and was assumed to be equal to AMS concentrate intake. This assumption is supported by past research demonstrating that the difference between the amount delivered and consumed is small when quantities of concentrate provided in the AMS are low $(<4 \mathrm{~kg} / \mathrm{d}$; Bach and Cabrera, 2017). Additionally, residual feed was collected and weighed from the AMS once daily during the adaptation periods and every $4 \mathrm{~h}$ during collection periods. On average, less than $40 \mathrm{~g} /$ cow per visit was removed from the AMS feeder during the collection periods. The AMS feeder was calibrated once weekly to ensure that the amount of concentrate dispensed was equal to the amount programmed. The calibration procedure included cleaning out the AMS feeder, dispensing and discarding one calibration sample to clear any debris or residue from the feeder, and then collecting 3 additional calibration samples directly from the feeder. An average weight of the last 3 samples was entered into the AMS computer system (Delpro 4.5, DeLaval).

For both housing groups, PMR was provided in 2 feedings, with $60 \%$ of their daily allocation at $0615 \mathrm{~h}$ and the remaining $40 \%$ at $1630 \mathrm{~h}$. The amount of PMR provided was adjusted to ensure ad libitum access to feed, with refusal targeted to equate to 5 to $10 \%$ (as-fed basis) of the amount of PMR offered. The quantity of PMR refused was measured once daily, approximately $30 \mathrm{~min}$ before feeding at $0615 \mathrm{~h}$. To ensure that the diet offered met DM formulations, forage ingredient DM content was determined twice weekly and other ingredients once weekly, as will be described.

\section{Data and Sample Collection}

The BW of each cow was measured on 2 consecutive days at the beginning of each period and again at the end of the study. Body weight was measured at $0930 \mathrm{~h}$ each day to minimize variability; however, with AMS systems, the time between $\mathrm{BW}$ measurement and the last milking event and PMR meal may differ among cows and across days. Body condition score was evaluated independently by 2 trained individuals on $\mathrm{d} 1$ and the final day of each period. Individual BCS was mea- 
Table 1. List of partial mixed ration (PMR) composition, chemical composition and particle size distribution of the diets provided to Holstein cows fed pelleted barley (PB) or steam-flaked barley (SFB) in an automated milking system (AMS)

\begin{tabular}{|c|c|c|}
\hline \multirow[b]{2}{*}{ Variable } & \multicolumn{2}{|c|}{ AMS treatment } \\
\hline & $\mathrm{PB}$ & SFB \\
\hline \multicolumn{3}{|c|}{ Dietary composition, $\%$ of DM } \\
\hline \multicolumn{3}{|c|}{ PMR } \\
\hline Barley silage & 26.61 & 26.61 \\
\hline Alfalfa hay & 15.21 & 15.21 \\
\hline Straw & 1.90 & 1.90 \\
\hline Beet pulp & 5.70 & 5.70 \\
\hline Steam-flaked barley & 15.21 & 15.21 \\
\hline Lactation pellet $^{1}$ & 26.61 & 26.61 \\
\hline Palmitic acid ${ }^{2}$ & 1.14 & 1.14 \\
\hline \multicolumn{3}{|l|}{ AMS concentrate } \\
\hline $\mathrm{PB}$ & 7.60 & - \\
\hline SFB & - & 7.60 \\
\hline \multicolumn{3}{|l|}{ Chemical composition ${ }^{3,4}$} \\
\hline $\mathrm{OM}, \%$ of $\mathrm{DM}$ & $87.21 \pm 0.39$ & $87.22 \pm 0.40$ \\
\hline $\mathrm{CP}, \%$ of DM & $17.85 \pm 0.55$ & $17.96 \pm 0.42$ \\
\hline $\mathrm{aNDF}_{\mathrm{OM}},{ }^{5} \%$ of $\mathrm{DM}$ & $32.57 \pm 1.28$ & $32.34 \pm 0.93$ \\
\hline $\mathrm{ADF}, \%$ of $\mathrm{DM}$ & $20.90 \pm 0.12$ & $20.72 \pm 0.21$ \\
\hline Starch, \% of DM & $25.01 \pm 1.44$ & $25.24 \pm 1.00$ \\
\hline NFC, $\%$ of DM & $39.54 \pm 1.57$ & $38.20 \pm 0.76$ \\
\hline Ether extract, $\%$ of DM & $4.61 \pm 0.28$ & $4.65 \pm 0.23$ \\
\hline $\mathrm{Ca}, \%$ of $\mathrm{DM}$ & $0.67 \pm 0.03$ & $0.68 \pm 0.02$ \\
\hline $\mathrm{P}, \%$ of $\mathrm{DM}$ & $0.35 \pm 0.01$ & $0.36 \pm 0.01$ \\
\hline $\mathrm{NE}_{\mathrm{L}}, \mathrm{Mcal} / \mathrm{kg}$ & $1.66 \pm 0.01$ & $1.67 \pm 0.00$ \\
\hline \multicolumn{3}{|c|}{ PMR particle size distribution, ${ }^{3} \%$ of total } \\
\hline$>19 \mathrm{~mm}$ & \multicolumn{2}{|c|}{$16.66 \pm 1.95$} \\
\hline$>8 \mathrm{~mm}$ & \multicolumn{2}{|c|}{$35.32 \pm 2.06$} \\
\hline$>4 \mathrm{~mm}$ & \multicolumn{2}{|c|}{$33.69 \pm 1.83$} \\
\hline $\operatorname{Pan}(<4 \mathrm{~mm})$ & \multicolumn{2}{|c|}{$14.33 \pm 1.94$} \\
\hline
\end{tabular}

${ }^{1}$ The lactation pellet contained $29.75 \%$ canola meal, $22.81 \%$ corn grain, $17.67 \%$ soybean meal, $13.71 \%$ peas, $6.01 \%$ soyhulls, $3.60 \%$ vitamin and mineral premix, $2.76 \%$ tallow, $1.60 \%$ sodium bicarbonate, $0.51 \%$ AmeriBond 2X (Borregaard AS) $0.46 \%$ limestone, 0.40\% Dyna-K (the Mosaic Company), 0.37\% urea, $0.34 \%$ Dynamate (the Mosaic Company), and $0.018 \%$ Rumensin (Elanco Animal Health). The vitamin and mineral premix included in the lactation pellet contained $30.8 \%$ dicalcium phosphate, $28.3 \%$ limestone, $16.0 \%$ salt, $12.3 \%$ magnesium oxide, $5.8 \%$ ground wheat, 3.9\% Dyna-K, $1 \%$ vegetable oil, $0.5 \%$ Sel-Plex 2000 (Alltech), $0.35 \%$ zinc oxide, $0.27 \%$ copper sulfate, $0.25 \%$ manganous oxide, $0.1 \%$ selenium (Masterfeeds), $0.009 \%$ cobalt sulfate, $0.04 \%$ iodine, $0.025 \%$ vitamin $\mathrm{A}, 0.016 \%$ vitamin $\mathrm{D}$, and $0.4 \%$ vitamin $\mathrm{E}$.

${ }^{2}$ Palmitic acid was supplied in the form of Energizer RP10 (Scothorn Nutrition).

${ }^{3}$ Period composites were analyzed with chemical composition and particle size distribution expressed as mean \pm SEM.

${ }^{4}$ Water was added to the PMR to achieve a DM content of $50 \%$.

${ }^{5} \mathrm{aNDF}_{\mathrm{OM}}=$ neutral detergent fiber analyzed using $\alpha$-amylase and sodium sulfite and corrected for ash content.

sured using a 5-point scale as described by Wildman et al. (1982) with the 2 observations averaged to yield a single value for each cow for each measurement event.

\section{DMI, PMR Sorting Behavior, and Feed Analyses}

For both housing groups, the amount of PMR offered and refused was determined daily on an as-fed basis. For cows in the LG housing group, cows were comingled with cows that were not enrolled in the study as their milking permissions changed during the course of the study. However, these cows were fed the same experimental treatments. As a result, PMR intake (corrected for DM) was determined at a housing group level and is reported for transparency, but no statistical analysis was conducted. As cows in the SM housing group were assigned to an individual bunk, the weights of the PMR offered and refused were recorded for each cow daily. A subsample of the daily refusal (20\% of the weight refused on an as-is basis) was collected and composited over the 6 -d collection period to derive a single sample for each cow.

The amount of concentrate delivered at each visit to the AMS was recorded by the computer software (Delpro 4.5, DeLaval). Samples of all feed ingredients, including AMS concentrates, were collected daily dur- 
ing the 6-d sample collection period and were stored at $-20^{\circ} \mathrm{C}$ until completion of the sampling period. At the end of the sampling period, daily feed samples were composited equally on an as-fed basis to yield one ingredient composite per period. Composited feed ingredients and refusal samples were dried in a forced-air oven at $55^{\circ} \mathrm{C}$ until achieving a constant weight for DM determination. Dry matter content of the feed ingredients was then used to determine the DM content of the PMR offered. For the SM housing group, individual PMR intake was calculated as the difference between PMR offered and PMR refused on a DM basis. For the LG housing group, PMR intake was determined by calculating the difference between total PMR offered and refused on a DM basis, divided by the number of cows housed in this housing group. For the SM housing group, AMS and PMR DMI were summed to calculate total DMI.

Dried concentrate samples were ground to pass through a 1-mm sieve using a centrifugal mill (ZM200; Retsch $\mathrm{GmbH}$ and Co. KG), and forage samples were ground to pass through a $1-\mathrm{mm}$ sieve using a hammer mill (Christie-Norris Laboratory Mill, Christy Turner Ltd.). Ground feed samples were sent to Cumberland Valley Analytical Services (Waynesboro, PA) for analysis of DM, CP, starch, ADF, NDF analyzed using $\alpha$-amylase and sodium sulfite corrected for ash content, and ether extract as described previously by Paddick et al. (2019).

Before being dried, a subsample of each composited feed ingredient and refusal sample for cows from the SM housing group was used to determine particle size distribution. Particle size distribution of each ingredient was measured in duplicate using the Penn State Particle Separator (Lammers et al., 1996) using sieves with 19-, 8-, and 4-mm apertures and a bottom pan (Nasco) using the method described by Kononoff et al. (2003). Particle size distribution of ingredients was then used to calculate the theoretical particle size distribution of the PMR offered. The actual quantity of particles consumed from each sieve of the Penn State Particle Separator was determined based on the difference between the quantity of particles refused from the quantity of particles offered in the PMR. The proportion of each fraction consumed was divided by the amount of the particle fraction that would have been consumed given the quantity of feed intake, assuming no sorting. These data were presented as a percentage as described by Leonardi and Armentano (2003). For each fraction, a sorting index greater than $100 \%$ indicates selective consumption, values equal to $100 \%$ indicate that no sorting occurred and actual intake was equal to predicted intake, and values less than $100 \%$ indicate sorting against the fraction.

\section{PMR Feeding Behavior}

For cows in the SM housing group, feed intake data from the Insentec feed bunks were collected by computer software (RIC Management Software, the Hokofarm Group) as validated by Chapinal et al. (2007). These data were used to determine PMR feeding behavior, including the number of meals (no./d), meal size (kg), meal duration $(\mathrm{min})$, and eating rate $(\mathrm{min} / \mathrm{kg}$ ). Raw data were reviewed, and visits without feed consumption were removed. The intermeal interval between each feed bunk visit was determined and $\log _{10}$ transformed (Tolkamp et al., 1998). Data were then analyzed to determine the meal criterion for each individual cow within period, using the procedure explained by DeVries et al. (2003) and the MIXDIST package (Macdonald and Green, 1988) of R software version 3.4.1 (https: //www.r-project.org/). The meal criterion was then used to determine the number of meals (no./d), eating time $(\mathrm{min} / \mathrm{d})$, meal duration ( $\mathrm{min} /$ meal), meal size $(\mathrm{kg} / \mathrm{meal})$, and rate of PMR consumption $(\mathrm{g} / \mathrm{min})$ for each cow daily. Data collected for each day of the 6-d sampling period was then averaged to yield one value per cow for each period.

\section{Milking Behavior, Milk Yield, and Milk Composition}

For the duration of the 6-d sample collection period, individual milk yield, number of AMS visits, milking duration, incomplete milkings where at least 1 quarter was not milked out completely, and number of milkings where the milker was kicked off were recorded by the AMS software (DelPro 4.5, DeLaval). The AMS software also recorded the number of daily sort gate passes and rejects for each cow, as well as the time spent in the holding area before entering the AMS. Averages for milk yield, milking behavior (voluntary visits, incomplete milkings, milking duration, and milking frequency) sort gate data, and holding area data were calculated over the 6 -d data collection period for each cow. The AMS was programmed to automatically collect samples $(24 \mathrm{~mL})$ for each cow from each milking event for the duration of the 6 -d sampling period. Samples were deposited into vials that were removed every $4 \mathrm{~h}$ over the 6 -d collection period and stored at $4^{\circ} \mathrm{C}$. For each cow, samples were composited proportionally by yield at each milking event into a daily 40-mL subsample using $2400 \mathrm{~h}$ as the cut-off between consecutive days. The composited samples (6 samples per cow in each period) were stored in a vial containing a preservative (Bronopol Microtab preservatives, Dairy Herd Improvement Laboratory) and stored at $4^{\circ} \mathrm{C}$ until being submitted to the Dairy Herd Improvement Laboratory (DHI, Edmonton, AB, Canada) for analysis of 
protein, fat, lactose, and MUN, which were determined using mid-infrared spectroscopy.

\section{Statistical Analysis}

Homogeneity of variance was tested for housing group and determined not to differ; as such, housing group was not included in the final statistical model. To test carry-over effects, data were analyzed using the fixed effects of treatment, order, and treatment $\times$ order interaction with the random effect of cow. With this model, the treatment $\times$ order interaction was not different $(P>0.10)$, with the exception of MUN $(P<$ 0.001 ), suggesting a lack of carry-over effects. Thus, data were analyzed using the Mixed model of SAS (version 9.3; SAS Institute Inc.), including the fixed effects of treatment, period, and milk yield measured before the start of the study, and the random effects of cow nested within treatment order and lactation (multiparous vs. primiparous). Data representing PMR intake, DMI, PMR feeding behavior, and PMR sorting index were restricted to cows from the SM housing group. Differences were considered significant when $P<0.05$, and tendencies are discussed when $0.10>P>0.05$. For PMR sorting behavior, a 2-tailed $t$-test was used to determine whether individual means differed from $100 \%$.

\section{RESULTS}

\section{DMI and Feeding Behavior}

Starting and ending BW and BCS were not different between AMS treatments $(P \geq 0.36$; Table 2$)$. For cows in the LG group, AMS intake did not differ among treatments. Likewise, AMS intake, PMR intake, and

Table 2. Effect of feeding pelleted barley (PB) or steam-flaked barley (SFB) in an automated milking system (AMS) on BW, BCS, DMI, AMS intake, and partial mixed ration (PMR) feeding behavior for Holstein cows ${ }^{1}$

\begin{tabular}{|c|c|c|c|c|}
\hline \multirow[b]{2}{*}{ Variable } & \multicolumn{2}{|c|}{ AMS treatment } & \multirow[b]{2}{*}{$\mathrm{SEM}^{2}$} & \multirow{2}{*}{$\begin{array}{l}P \text {-value, } \\
\text { treatment }\end{array}$} \\
\hline & $\mathrm{PB}$ & SFB & & \\
\hline $\mathrm{n}^{1}$ & 29 & 29 & - & - \\
\hline \multicolumn{5}{|l|}{ BW, kg } \\
\hline Starting & 675 & 683 & 8.24 & 0.49 \\
\hline Ending & 693 & 682 & 8.2 & 0.36 \\
\hline \multicolumn{5}{|l|}{$\mathrm{BCS}^{3} \mathrm{O}$} \\
\hline Starting & 3.13 & 3.15 & 0.014 & 0.32 \\
\hline Ending & 3.16 & 3.13 & 0.018 & 0.33 \\
\hline AMS intake, $\mathrm{kg}$ of $\mathrm{DM} / \mathrm{d}$ & 1.98 & 1.99 & 0.033 & 0.84 \\
\hline $\mathrm{n}^{1}$ & 14 & 14 & & \\
\hline Total DMI,${ }^{4} \mathrm{~kg} / \mathrm{d}$ & 29.7 & 28.4 & 1.28 & 0.48 \\
\hline AMS intake, ${ }^{4} \mathrm{~kg}$ of $\mathrm{DM} / \mathrm{d}$ & 2.00 & 2.07 & 0.038 & 0.23 \\
\hline PMR intake, ${ }^{4} \mathrm{~kg}$ of $\mathrm{DM} / \mathrm{d}$ & 27.7 & 26.3 & 1.27 & 0.45 \\
\hline \multicolumn{5}{|l|}{ PMR feeding behavior ${ }^{5}$} \\
\hline Meals, no./d & 5.9 & 6.2 & 0.50 & 0.60 \\
\hline Eating time, $\min / \mathrm{d}$ & 215.6 & 204.1 & 19.28 & 0.31 \\
\hline Meal duration, min/meal & 38.0 & 34.4 & 3.82 & 0.23 \\
\hline Meal size, $\mathrm{kg} /$ meal & 4.92 & 4.51 & 0.345 & 0.28 \\
\hline Eating rate, $\mathrm{g} / \mathrm{min}$ & 135.4 & 129.2 & 13.06 & 0.30 \\
\hline \multicolumn{5}{|l|}{ PMR sorting index, ${ }^{5,6} \%$} \\
\hline$>19 \mathrm{~mm}$ & 100.8 & 103.0 & 3.29 & 0.58 \\
\hline$>8 \mathrm{~mm}$ & 100.6 & 99.9 & 0.79 & 0.58 \\
\hline$>4 \mathrm{~mm}$ & $105.1^{\mathrm{a}}$ & $108.9^{\mathrm{b}}$ & 2.92 & 0.38 \\
\hline $\operatorname{Pan}(<4 \mathrm{~mm})$ & $83.8^{\mathrm{a}}$ & $74.38^{\mathrm{a}}$ & 8.36 & 0.42 \\
\hline
\end{tabular}

${ }^{a}$ Mean is significantly different from a sorting index of $100(P<0.05)$.

${ }^{\mathrm{b}}$ Tendency for the mean to be different from a sorting index of $100(P<0.10)$.

${ }^{1}$ The study was conducted using a total of 29 cows that were housed in a large group with up to additional 18 cows in a freestall barn. An additional small group of 7 cows were housed in a freestall pen.

${ }^{2}$ Largest SEM is reported.

${ }^{3} \mathrm{BCS}$ was measured according to Wildman et al. (1982), using a 5-point scale.

${ }^{4}$ Total DMI is the sum of PMR and AMS intake.

${ }^{5}$ PMR intake, PMR feeding behavior, and PMR sorting behavior were measured only for the SM housing group.

${ }^{6}$ Sorting index was calculated according to Leonardi and Armentano (2003), where values greater than 100 indicate selective consumption, values equal to 100 indicate that no sorting occurred, and values less than 100 indicate selective avoidance. 
total DMI did not differ among treatments $(P \geq 0.23)$. Cows in both treatment groups consumed the expected amount of pellet in the AMS.

For PMR feeding behavior, measured only in the SM group, PMR meals $(P=0.60)$, eating time $(P=$ $0.31)$, meal duration $(P=0.23)$, meal size $(P=0.28)$, and eating rate $(P=0.30)$ were not affected by AMS treatment. We also found no difference in PMR sorting behavior for particles $>19 \mathrm{~mm}(P=0.58),>8 \mathrm{~mm}(P$ $=0.58),>4 \mathrm{~mm}(P=0.38)$, and $<4 \mathrm{~mm}(P=0.42)$ between cows fed PB or SFB in the AMS. However, cows offered PB in the AMS selectively consumed particles $>4 \mathrm{~mm}(P=0.001)$, whereas cows offered SFB only tended to selectively consume particles $>4 \mathrm{~mm}(P=$ 0.055). Both cows fed PB and SFB selectively avoided particles $<4 \mathrm{~mm}(P \leq 0.046)$.

\section{Milking Activity, Milk Yield, and Milk Composition}

Cows receiving SFB had fewer AMS visits than those receiving $\mathrm{PB}(P=0.012$; Table 3$)$. Despite the reduction in AMS visits for SFB, we observed no effect of treatment on milk yield $(P=0.47)$, fat yield $(P=$ $0.53)$, or crude protein yield $(P=0.31)$. Furthermore, we found no effects of AMS concentrate type on milk fat, crude protein, lactose, or MUN concentrations.

The average interval between milkings was longer for cows receiving SFB than for those offered $\mathrm{PB}(P=$ 0.031). Cows receiving SFB had lower total daily box time than those fed PB $(P=0.002)$, but box time per milking was not different. We found no treatment effect on incidence of incomplete milkings or kickoffs. Cows receiving SFB spent more total time in the holding area and before each milking than those receiving $\mathrm{PB}$.

\section{DISCUSSION}

Provision of a palatable feed in the AMS during milking is considered one of the main factors, aside from barn design, responsible for maintaining frequent and consistent AMS attendance. As such, recommendations, published in a conference proceeding, suggest offering larger quantities of concentrate in the AMS, based on the perception that motivation to enter the AMS increases by offering a greater reward (Rodenburg, 2011). Although the number of studies focusing on AMS feeding strategies are increasing, few studies have compared the effects of the form of concentrate provision in the AMS on voluntary AMS attendance or milk production. The current study aimed to determine the effects of offering $\mathrm{PB}$ versus SFB in the AMS on milking behavior, milk and milk component yield, and PMR feeding behavior at a low AMS feeding level.

It has been suggested that pellet quality and pellet composition may affect motivation for cows to visit the AMS. Migliorati et al. (2005) found that offering a flavored pellet increased visits to the preselection gate, but that such a response was not observed when low quantities $(1.4 \mathrm{~kg} / \mathrm{d})$ of pellet were provided. These results suggest that, although pellet composition may affect preference or palatability, such effects may not have as much influence when low or moder-

Table 3. Effect of feeding pelleted barley (PB) or steam-flaked barley (SFB) in an automated milking system (AMS) on milking frequency, milking behavior, holding area durations, sort gate events, and milk and milk component yield for Holstein cows ${ }^{1}$

\begin{tabular}{lcccc}
\hline & \multicolumn{2}{c}{ AMS treatment } & & \\
\cline { 2 - 3 } Variable & PB & SFB & SEM $^{2}$ & $\begin{array}{c}P \text {-value, } \\
\text { treatment }\end{array}$ \\
\cline { 2 - 3 } $\mathrm{n}$ & & 43 & - & - \\
Milking frequency, no./d & 2.90 & 2.71 & 0.051 & 0.012 \\
Milk yield, kg/d & 43.9 & 43.5 & 0.44 & 0.47 \\
Fat, kg/d & 1.60 & 1.59 & 0.014 & 0.53 \\
Crude protein, kg/d & 1.45 & 1.43 & 0.015 & 0.31 \\
Milk composition & & & & \\
Fat, \% & 3.69 & 3.68 & 0.02 & 0.71 \\
Protein, \% & 3.33 & 3.31 & 0.016 & 0.26 \\
Lactose, \% & 4.71 & 4.71 & 0.010 & 0.68 \\
MUN, mg/dL & 13.84 & 14.09 & 0.158 & 0.26 \\
Inter-milking interval, min & 505.8 & 541.7 & 21.02 & 0.031 \\
Total box time, min/d & 21.4 & 19.7 & 0.35 & 0.002 \\
Average box time, min/milking & 7.53 & 7.61 & 0.68 & 0.51 \\
Incomplete milkings, \% of milkings/d & 3.09 & 2.91 & 0.634 & 0.83 \\
Kickoffs, \% of milkings/d & 7.23 & 6.43 & 0.99 & 0.55 \\
Duration in holding area, min/d & 81.2 & 139.9 & 11.68 & 0.001 \\
Duration in holding area, min/milking & 32.1 & 61.1 & 5.62 & 0.001 \\
\hline
\end{tabular}

${ }^{1}$ Data were analyzed utilizing prestudy milk yield as a covariate.

${ }^{2}$ Largest SEM is reported. 
ate quantities are fed. Based on these findings, it has been hypothesized that concentrate form may not be as important when low concentrate feeding rates are implemented in AMS and that simpler pellet formulations could be accepted (Madsen et al., 2010; Henriksen et al., 2018). In the present study, adequate voluntary AMS visiting frequency was observed despite no additional ingredients in the concentrates beyond barley. Although we found no difference in AMS concentrate consumption between treatments, observed changes in milking behavior suggest a preference for $\mathrm{PB}$ over SFB. Cows offered SFB displayed decreased AMS visits, tended to have longer intervals between milkings, had decreased total box time, and spent longer in the holding area. Despite speculation that allocating only a small quantity of AMS concentrate (i.e., $2 \mathrm{~kg} / \mathrm{d}$ on a DM basis) would allow more room for flexibility in the form of concentrate being provided, this assumption does not appear to be supported by the current study.

It is unclear why cows in the present study preferred PB over SFB, particularly given that the barley originated from the same source and that both treatments likely induced at least partial starch gelatinization. Kertz et al. (1981) compared corn and wheat middlingbased supplements differing in form and reported that the pelleted ration was consumed more rapidly than crumbled pellet and meal forms. Furthermore, many of the differences in that study occurred within the first 8 min of treatment exposure, a timeline similar to that in AMS considering box time for each milking event. Responses in the study of Kertz et al. (1981) were attributed to greater bulk density with pelleting, which appears to be a different driving factor for the current study, given that we observed similar intakes of $\mathrm{PB}$ and SFB. In a different study, Spörndly and Åsberg (2006) reported greater palatability for pelleted supplements over ground barley and more generally concluded that pelleted feeds are most preferred by dairy cattle. The rationale behind these preference choices are not fully understood, but the current study supports the previous findings that pelleted feed is preferred over steamflaked feed, in this case with barley.

Others have reported differences in voluntary attendance to the AMS correlated with composition and structure of the concentrate provided. For example, Henriksen et al. (2018) reported increased AMS attendance when a mixture of pelleted and rolled barley was offered, relative to a pelleted concentrate. Madsen et al. (2010) determined that cows preferred pellets containing wheat or a barley-oat mixture, as demonstrated by increased AMS visits, concentrate intake, and milk yield when provided those treatments. Finally, Moore et al. (2020) observed that use of liquid feed in the
AMS did not affect voluntary attendance relative to cows not receiving the liquid feed. Based on variability in responses from the previously mentioned studies and the current study, an improved understanding of factors motivating cows to visit the AMS is needed.

Despite a decrease in AMS visits, we observed no difference in milk yield between the 2 treatment groups. It is possible that, although decreased milking frequency is associated with decreased milk yield (Stelwagen et al., 2013), the period duration of 21 or 28 d may not have been sufficient to observe a decline in milk yield or that the decline in frequency was not great enough to elicit a change in milk yield, given that cows in this study represented a wide range for DIM. One frequently cited benefit of transitioning to an AMS system is the potential to increase milk yield, primarily through increased milking frequency relative to systems where cows are milked twice daily (Rodenburg, 2011; Tremblay et al., 2016). In addition, the current study was conducted in a guided-flow barn, which may partially minimize the effects of cattle preference or motivation to access the AMS, as they are directed to the AMS holding area if milking permissions allow when moving from the feeding area to the freestall area. Nevertheless, the increased time spent in the holding area and decreased visits to the AMS are interpreted to indicate lower motivation to enter the AMS. We speculate that, had this study been conducted in a free-flow barn, the decreased AMS visits might have equated to a more pronounced reduction in voluntary AMS visits, increasing the need to fetch cows, and subsequently decreasing milk yield. However, this speculation remains to be tested.

As mentioned previously, when offered SFB, cows spent a longer time in the holding pen, whether reported as time per visit or total time per day. Time spent in the holding area could otherwise be spent carrying out other daily activities. Though cows fed SFB spent more time in the AMS holding area, we detected no effect on PMR intake or feeding behavior, suggesting that other activities such as lying time may have been altered. However, lying time was not measured in this study, and therefore this suggestion cannot be confirmed. Part of the altered behavior was mediated by decreased total box time due to lesser milking frequency and lack of differences in box time per milking when fed SFB compared with PB. Future work is needed to evaluate how concentrate feeding strategies affect behavioral patterns of dairy cows in AMS settings and whether the responses differ among guided traffic and free traffic designs.

To our knowledge, this is the first study where concentrate form and PMR sorting behavior were both evaluated under an AMS context. Although no effect 
of treatment on sorting behavior was detectable, cows sorted for particles retained on the 4-mm sieve and sorted against particles on the pan. These findings are similar to those of Paddick et al. (2019), which demonstrated that cows offered 0.5 or $2.0 \mathrm{~kg} / \mathrm{d}$ of AMS concentrate also sorted for particles retained on the $4-\mathrm{mm}$ sieve, and those offered $0.5 \mathrm{~kg} / \mathrm{d}$ sorted against particles $<4 \mathrm{~mm}$. Paddick et al. (2019) also observed that increasing the quantity of concentrate $(0.5,2.0,3.5$, or $5.0 \mathrm{~kg}$ ) in the AMS linearly increased sorting against particles retained on the $19-\mathrm{mm}$ sieve and linearly decreased their sorting against particles retained on the pan. In another study, Hare et al. (2018) found that when 0.5 or $5.0 \mathrm{~kg}$ of concentrate was provided in the AMS, cows offered $5.0 \mathrm{~kg}$ sorted for particles retained on the 8-mm sieve and against particles retained on the pan relative to those offered $0.5 \mathrm{~kg}$ of concentrate in the AMS. The results of the present study, when combined with previous studies, suggest that quantity, not type, of AMS concentrate may alter PMR sorting behavior.

\section{CONCLUSIONS}

Our results indicate that for cows housed in a feedfirst guided traffic flow system, feeding $\mathrm{PB}$ versus SFB in the AMS does not influence AMS concentrate intake or PMR eating behavior when cows are fed a low quantity of AMS concentrate. However, offering SFB resulted in decreased AMS visits, increased interval between milkings, increased time spent in the holding area, and decreased total box time. Although no effect on milk yield was observed, these changes in milking behavior may translate to lost milk production depending on stage of lactation. The results of this study indicate that the form of concentrate provided in the AMS is associated with motivation to enter the AMS. Therefore, use of a pelleted concentrate in AMS may help to encourage voluntary visits to the AMS and reduce time associated with nonproductive behavior, even in a guided traffic flow barn.

\section{ACKNOWLEDGMENTS}

Funding for this study was provided by the Alberta Livestock and Meat Agency (Edmonton, AB, Canada), Alberta Milk (Edmonton, AB, Canada), Dairy Farmers of Manitoba (Winnipeg, MB, Canada), the Saskatchewan Ministry of Agriculture through the Agriculture Development Fund (Regina, SK, Canada), and SaskMilk (Regina, SK, Canada). The authors acknowledge P. Yu (University of Saskatchewan, Saskatoon, SK, Canada) for providing advice on statistical analysis. The authors have not stated any conflicts of interest.

\section{REFERENCES}

Bach, A., and V. Cabrera. 2017. Robotic milking: Feeding strategies and economic returns. J. Dairy Sci. 100:7720-7728. https://doi .org/10.3168/jds.2016-11694.

Bach, A., M. Devant, C. Igleasias, and A. Ferrer. 2009. Forced traffic in automatic milking systems effectively reduces the need to get cows, but alters eating behavior and does not improve milk yield of dairy cattle. J. Dairy Sci. 92:1272-1280. https://doi.org/10.3168/ jds.2008-1443.

Castro, A., J. M. Pereira, C. Amiama, and J. Bueno. 2012. Estimating efficiency in automatic milking systems. J. Dairy Sci. 95:929-936. https://doi.org/10.3168/jds.2010-3912.

Chapinal, N., D. M. Veira, D. M. Weary, and M. A. G. von Keyserlingk. 2007. Technical note: Validation of a system for monitoring individual feeding and drinking behaviour and intake in group housed dairy cows. J. Dairy Sci. 90:5732-5736. https://doi.org/10 $.3168 /$ jds.2007-0331.

de Jong, W., A. Finnema, and D. J. Reinemann. 2003. Survey of management practices of farms using automatic milking systems in North America. Pages 1-11 in Proc. 2003 ASAE Annual International Meeting, Las Vegas, NV. American Society of Agricultural and Biological Engineers.

de Koning, C. J. A. M. 2011. Milking machines: Robotic milking. Pages 952-958 in Encyclopedia of Dairy Sciences. 2nd ed. J. W. Fuquay, ed. Academic Press.

Deming, J. A., R. Bergeron, K. E. Leslie, and T. J. DeVries. 2013. Associations of cow-level factors, frequency of feed delivery, and standing and lying behavior of dairy cows milked in an automatic system. Can. J. Anim. Sci. 93:427-433. https://doi.org/10.4141/ cjas2013-055.

DeVries, T. J., M. A. G. von Keyserlingk, D. M. Weary, and K. A. Beauchemin. 2003. Measuring the feeding behavior of lactating dairy cows in early to peak lactation. J. Dairy Sci. 86:3354-3361. https://doi.org/10.3168/jds.S0022-0302(03)73938-1.

Halachmi, I., E. Shoshani, R. Solomon, E. Maltz, and J. Miron. 2006. Feeding of pellets rich in digestible neutral detergent fiber to lactating cows in an automatic milking system. J. Dairy Sci. 89:32413249. https://doi.org/10.3168/jds.S0022-0302(06)72599-1.

Hare, K., T. J. DeVries, K. S. Schwartkopf-Genswein, and G. B. Penner. 2018. Does the location of concentrate provision affect voluntary visits, and milk and milk component yield for cows in an automated milking system? Can. J. Anim. Sci. 98:399-404. https: //doi.org/10.1139/cjas-2017-0123.

Henriksen, J. C. S., L. Munksgaard, and M. R. Weisbjerg. 2018. Short-term responses in production and behavior during periods of change in concentrate allowance for dairy cows. J. Dairy Sci 101:7942-7953. https://doi.org/10.3168/jds.2018-14624.

Henriksen, J. C. S., M. R. Weisbjerg, P. Løvendahl, T. Kristensen, and L. Munksgaard. 2019. Effects of an individual cow concentrate strategy on production and behavior. J. Dairy Sci. 102:2155-2172. https://doi.org/10.3168/jds.2018-15477.

Jacobs, J. A., and J. M. Siegford. 2012. Invited review: The impact of automated milking systems on dairy cow management, behavior, health, and welfare. J. Dairy Sci. 95:2227-2247. https://doi.org/ $10.3168 /$ jds.2011-4943

Kertz, A. F., B. K. Darcy, and L. R. Prewitt. 1981. Eating rate of lactating cows fed four physical forms of the same grain ration. J. Dairy Sci. 64:2388-2391. https://doi.org/10.3168/jds.S0022 $-0302(81) 82861-5$

Kononoff, P. J., A. J. Heinrichs, and D. R. Buckmaster. 2003. Modification of the Penn State Forage and Total Mixed Ration Particle Separator and the effects of moisture content on its measurements. J. Dairy Sci. 86:1858-1863. https://doi.org/10.3168/jds.S0022 -0302(03)73773-4.

Lammers, B. P., D. R. Buckmaster, and A. J. Heinrichs. 1996. A simple method for the analysis of particle sizes of forage and total mixed rations. J. Dairy Sci. 79:922-928. https://doi.org/10.3168/ jds.S0022-0302(96)76442-1.

Leonardi, C., and L. E. Armentano. 2003. Effect of quantity, quality, and length of alfalfa hay on selective consumption by dairy 
cows. J. Dairy Sci. 86:557-564. https://doi.org/10.3168/jds.S0022 -0302(03)73634-0.

Macdonald, P. D. M., and P. E. J. Green. 1988. User's guide to program MIX: An interactive program for fitting mixtures of distributions. Release 2.3. Accessed Apr. 6, 2020. https://ms.mcmaster .ca/peter/mix/MIX23_Users_Guide.pdf.

Madsen, J., M. R. Weisbjerg, and T. Hvelplund. 2010. Concentrate composition for automatic milking systems-Effect on milking frequency. Livest. Sci. 127:45-50. https://doi.org/10.1016/j.livsci 2009.08.005

Matson, R. D., M. T. M. King, T. F. Duffield, D. E. Santschi, K. Orsel, E. A. Pajor, G. B. Penner, T. Mutsvangwa, and T. J. DeVries. 2021. Benchmarking of farms with automated milking systems in Canada and associations with milk production and quality. J. Dairy Sci. 104:7971-7983. https://doi.org/10.3168/jds.2020-20065.

Menajovsky, S. B., C. E. Walpole, T. J. DeVries, K. S. SchwartzkopfGenswein, M. E. Walpole, and G. B. Penner. 2018. The effect of the forage-to-concentrate ratio of the partial mixed ration and the quantity of concentrate in an automatic milking system for lactating Holstein cows. J. Dairy Sci. 101:9941-9953. https://doi.org/10 $.3168 /$ jds.2018-14665

Migliorati, L., M. Speroni, S. Lolli, and F. Calza. 2005. Effect of concentrate feeding on milking frequency and milk yield in an automatic milking system. Ital. J. Anim. Sci. 4(Suppl. 2):221-223. https://doi.org/10.4081/ijas.2005.2s.221.

Moore, S. M., M. T. M. King, A. J. Carpenter, and T. J. DeVries. 2020. Behavior, health, and productivity of early-lactation dairy cows supplemented with molasses in automated milking systems. J. Dairy Sci. 103:10506-10518. https://doi.org/10.3168/jds.2020 $-18649$.

Paddick, K. S., T. J. DeVries, K. Schwartzkopf-Genswein, M. A. Steele, M. E. Walpole, and G. B. Penner. 2019. Effect of the amount of concentrate offered in an automated milking system on dry matter intake, milk yield, milk composition, ruminal digestion, and behavior of primiparous Holstein cows fed isocaloric diets. J. Dairy Sci. 102:2173-2187. https://doi.org/10.3168/jds.2018-15138.
Rodenburg, J. 2011. Designing feeding systems for robotic milking. Pages 127-136 in Proc. Tri-State Dairy Nutrition Conference.

Salfer, J., M. Endres, W. Lazarus, K. Minegishi, and B. Berning. 2019. Dairy robotic milking systems - What are the economics? Accessed Mar. 1, 2021. https://dairy-cattle.extension.org/dairy -robotic-milking-systems-what-are-the-economics/.

Spörndly, E., and T. Åsberg. 2006. Eating rate and preference of different concentrate components for cattle. J. Dairy Sci. 89:21882199. https://doi.org/10.3168/jds.S0022-0302(06)72289-5.

Stelwagen, K., C. V. C. Phyn, S. R. Davis, J. Guinard-Flament, D. Pomiès, J. R. Roche, and J. K. Kay. 2013. Invited review: Reduced milking frequency: Milk production and management implications. J. Dairy Sci. 96:3401-3413. https://doi.org/10.3168/jds.2012-6074.

Tolkamp, B. J., D. J. Allcroft, E. J. Austin, B. L. Nielsen, and I. Kyriazakis. 1998. Satiety splits feeding behavior into bouts. J. Theor. Biol. 194:235-250. https://doi.org/10.1006/jtbi.1998.0759.

Tremblay, M., J. P. Hess, B. M. Christenson, K. K. McIntyre, B. Smink, A. J. van der Kamp, L. G. de Jong, and D. Döpfer. 2016. Factors associated with increased milk production for automatic milking systems. J. Dairy Sci. 99:3824-3837. https://doi.org/10 $.3168 /$ jds.2015-10152.

Wildman, E. E., G. M. Jones, P. E. Wagner, R. L. Boman, H. F. Troutt Jr., and T. N. Lesch. 1982. A dairy cow body condition scoring system and its relationship to selected production characteristics. J. Dairy Sci. 65:495-501. https://doi.org/10.3168/jds .S0022-0302(82)82223-6

\section{ORCIDS}

J. A. Johnson (ํ) https://orcid.org/0000-0003-2177-5107

M. Gardner () https://orcid.org/0000-0002-5697-7799

G. B. Penner (ㄴ) https://orcid.org/0000-0002-6396-2130 